\title{
Una vida en Chile y seguir siendo extranjeros*
}

\author{
A lifetime living in Chile yet still a foreigner
}

\author{
Carolina Stefoni ${ }^{\star *}$ \\ Macarena Bonhomme $e^{* * *}$ \\ Universidad Alberto Hurtado, Santiago, Chile
}

Recibido: 9 de julio de 2014. Aprobado: 7 de octubre de 2014.

\section{Resumen}

Han pasado cerca de 20 años desde que comenzó a modificarse el patrón migratorio en Chile, y durante ese tiempo los y las migrantes han ido construyendo múltiples trayectorias en el país. La forma en cómo se construyen estas trayectorias está condicionada por factores económicos, políticos y culturales que encuentran los sujetos en las sociedades de destino y de origen. A su vez, estas trayectorias dan cuenta de procesos disímiles de inserción en las sociedades. En este artículo exploramos cómo se construyen y experimentan los procesos de inserción de mujeres migrantes en Chile. A través de sus trayectorias y relatos de vida, sostenemos que los procesos de inserción tienden a estar marcados por una dimensión que adquiere mayor protagonismo y que contribuye a dar sentido a la experiencia migratoria. El trabajo, la familia y las redes sociales son las dimensiones que articulan estas distintas trayectorias, las cuales serán analizadas en este artículo.

Palabras claves: migración, inserción, trayectorias de vida.

Artículo elaborado en el marco del Proyecto FIUC (Federación Internacional de Universidades Católicas) "El papel del capital social de los migrantes en el desarrollo humano de las sociedades latinoamericanas" y el Proyecto Fondecyt $\mathrm{N}^{\circ} 1130642$. Se agradece a su vez el apoyo del Centro de Estudios de Conflicto y Cohesión Social (COES) CONICYT/FONDAP/15130009.

** PhD en Sociología, Universidad Alberto Hurtado, magíster en Estudios Culturales, Universidad de Birmingham, socióloga, Pontificia Universidad Católica de Chile. Directora del Departamento de Sociología de la Universidad Alberto Hurtado, Santiago, Chile. Cienfuegos 460. Correo electrónico: cstefoni@uahurtado.cl

*** Estudiante PhD en Sociología Goldsmiths, University of London, magíster en Cultura y Sociedad, London School of Economics, socióloga, Pontificia Universidad Católica de Chile. Académica asociada del Magíster en Psicología Social de la Universidad Alberto Hurtado, Santiago, Chile, Cienfuegos 460. Correo electrónico: m.bonhomme@gold.ac.uk 


\begin{abstract}
It has been twenty years since the migratory pattern in Chile started to change. Meanwhile, many migrants have been constructing multiple trajectories in the country. The way in which these trajectories have been constructed is influenced by economic, political and cultural factors that migrants face in both the host society and the society of origin. At the same time, these trajectories show different processes of inclusion in these societies. The aim of this paper is to explore how these processes are experienced and constructed by migrant women in Chile. Based on their life stories, we suggest that the processes of inclusion tend to be marked by a dimension that acquires a greater role and contributes to understand their experiences of migration. Work, family and social networks frame such diverse trajectories, which will be analyzed in this paper.
\end{abstract}

Keywords: migration, inclusion, life trajectories.

\title{
Introducción
}

A mediados de los 90, Chile comenzó a experimentar un incremento sostenido en el número de inmigrantes, principalmente de origen latinoamericano (Martínez, 2003; Cano, Soffia y Martínez, 2009; Stefoni, 2011). En los años siguientes este flujo ha continuado creciendo, observándose también una diversificación en su origen nacional. Han pasado dos décadas desde que este nuevo patrón migratorio comenzó a gestarse y, durante este tiempo, se han analizado diversos procesos asociados a estos movimientos de población, tales como la feminización de la migración (Tijoux, 2013a; Mora, 2008, 2009; Godoy, 2007), su inserción en mercados de trabajo y los consecuentes proceso de segmentación laboral (Stefoni y Fernández, 2011; Garcés, 2014; Staab y Maher, 2006; Mujica, 2004), discriminación y exclusión (Thayer, 2013; Tijoux, 2013a; Becerra, 2012), cuidado e infancia (Pavéz, 2012, 2013; Acosta, 2013; Tijoux 2007), espacios urbanos, espacios privados y migración (Ducci y Rojas, 2010; Imilan, 2013; Garcés, 2013, 2014; Bonhomme, 2013), migración y fronteras (Tapia 2012; Guizardi, 2013), entre otros. Durante estos años, la vida de los y las migrantes ha continuado su curso, y en esas trayectorias muchos comenzaron a echar raíces en una tierra que en principio parecía lejana. El nacimiento de hijos y nietos, la obtención de una casa propia, la estabilidad laboral y la construcción de redes sociales, son mecanismos que han favorecido procesos de arraigo y de anclaje en un mundo extraño, volviendo lo desconocido e incierto en algo familiar y cercano. 
Estos procesos de anclaje no suponen el reemplazo de aquello que quedó atrás. La experiencia de vida de los y las migrantes nos enseña que más que mundos excluyentes y polarizados (aquí o allá), la vida cotidiana se va construyendo a través de anclajes multisituados y transfronterizos, que van dando forma a un estar simultáneo "en el aquí y en el allá" (Levitt y Glick Schiller, 2004).

Uno de los conceptos utilizados para comprender las resignificaciones identitarias que se desarrollan durante la experiencia migratoria es el de hibridación (Canclini, 1990), que en términos amplios consiste en el proceso sociocultural mediante el cual emergen nuevas estructuras y prácticas producto de la combinación con aquellas ya existentes. Sin embargo, sostendremos que los procesos de anclajes multisituados y la pertenencia simultánea que se produce a partir de la fractura que introduce la experiencia migratoria, no queda resuelta necesariamente a través de este concepto. En la vida de los y las migrantes no siempre se produce una síntesis entre ambos mundos — de origen y destino-, sino que muchas veces la escisión termina siendo parte de la experiencia migratoria, generando distintas formas de pertenecer que se reconstruyen en la cotidianeidad. En este sentido, los conceptos de "tercer espacio" o "in-betweenness" de Bhabha (1996), permiten aproximarnos a la comprensión de la experiencia migratoria, en tanto plantea la potencialidad de ambas culturas de contenerse, a la vez que permite develar las fronteras que las separan. El concepto alude a la experiencia de aquellos migrantes que viven en este tercer espacio, en un estar aquí y allá, sin pertenecer completamente a ningún lugar. Y es esa escisión la que intentan conciliar cotidianamente a través de múltiples arraigos que ejemplifican su-estar-entre ambos mundos, y que define las formas que adquiere la inserción en las sociedades de destino.

El interés que tenemos en este artículo es comprender en qué consiste y cómo se despliegan los procesos de anclaje e inserción social dentro de la sociedad de llegada, qué elementos o ejes favorecen este proceso, y de qué modo estos permiten la vinculación con el lugar de origen, posibilitando el desarrollo de pertenencias simultáneas. Nuestra hipótesis es que el anclaje en las sociedades de llegada se produce a través de tres ejes: el trabajo, la familia y las redes sociales. Cada uno de ellos adquiere distinto protagonismo en las trayectorias de las personas migrantes, lo que va marcando el proceso de inserción que experimentan. Si bien existen otros ejes que logran articular el proceso de inserción, tales como la ciudadanía, nos enfocaremos en estos tres, pues son los que aparecen con mayor fuerza en los relatos realizados. En este artículo, por tanto, exploramos desde la perspectiva del sujeto, a través de un análisis narrativo temático, las múltiples formas de inserción que experimentan mujeres migrantes en Santiago de Chile, entendiendo que 
no se trata de un proceso lineal ni predeterminado, sino de uno mucho más complejo donde estos ejes se entrecruzan, adquiriendo diversas intensidades y relevancias.

Para llevar adelante esta reflexión se construyeron y analizaron relatos de vida de tres mujeres de origen peruano que viven hace más de 15 años en Chile, todas con visa definitiva en el país. Tres mujeres que llegaron solas y que al cabo de un tiempo formaron una familia, ya sea a través de un proceso de reunificación o porque conocieron a su pareja estando en Chile. Cada relato presenta una estructura en la que emerge una dimensión central que logra articular la narración, organizar los acontecimientos y enfatizar determinadas etapas o momentos de la vida de las personas. Estas dimensiones son: trabajo, familia y redes sociales; y si bien la tres están presentes en los relatos, las mujeres tienden a enfatizar una de ellas. Nuestra hipótesis es que esta dimensión, este hilo conductor que articula el relato, es el elemento sobre el cual se va construyendo el proceso de anclaje e integración en el mundo local chileno y en el mundo de origen.

Esta aproximación permite problematizar nociones más clásicas sobre integración que tienden a asumir demasiado rápido la existencia de sujetos homogéneos, neutrales y sin contradicciones. Lo que esperamos aportar a la discusión es precisamente la problematización y diferenciación que emerge en los procesos de inserción social de los y las migrantes en la sociedad receptora.

Las trayectorias que se despliegan en el relato de las entrevistadas están relacionadas con el lugar social, económico y simbólico que ocupa la mujer en las sociedades de pertenencia, tanto de llegada como de origen. En este sentido, la condición de extranjera (Simmel, 1986) o extraña (Beck, 2000) incide en la forma y significados que adquiere la trayectoria de vida. Todorov (1990) argumenta que el ser extranjero no es una cualidad intrínseca, sino que es una condición otorgada por los nativos y, por ende, en el concepto subyace la mirada de la persona local, llevando aparejados múltiples juicios. Así, juzgar la cultura extranjera es jerarquizar tal cultura con respecto a la cultura del país receptor. Las trayectorias, por tanto, responden en gran medida a las condiciones sociales, económicas, políticas y culturales que enfrentan los sujetos en las sociedades de destino y origen.

Introdujimos en este capítulo pequeños fragmentos de las entrevistas que van dando cuenta de cómo estos tres ejes articulan el proceso de inserción social y cultural en la sociedad receptora y la vinculación cotidiana con el lugar de origen. 


\section{Beatriz. Trabajo como eje de inserción}

Beatriz tiene 46 años y proviene de Chincha, una ciudad situada al sur de Lima. Está casada y tiene un hijo, quien a su vez está casado con una mujer peruana con quien tiene una hija. Todos viven en Chile. Beatriz fue la primera en llegar, de eso hace 16 años.

Ella llegó a Chile buscando trabajo. Había quedado de encontrarse con su prima en el terminal de buses. Sin embargo, eso no ocurrió. Gracias a las indicaciones que tenía en un papel, logró salir del terminal y llegar a una casa pastoral donde había otras mujeres migrantes que le ayudaron a conseguir trabajo. Comenzó como asesora del hogar puertas adentro, enfrentando los problemas que derivan de las características de este trabajo: la no-separación entre espacio público y privado y una ambigua definición de las labores domésticas, lo que conlleva muchas veces hacerse cargo de todo el trabajo necesario para la reproducción del hogar, es decir, alimentación, limpieza, cuidado y cariño (Hondagneu Sotello, 2007; Russell Hochschild, 2000; Stefoni y Fernández, 2011).

Los primeros meses en Chile fueron un período de ajuste, soledad y nostalgia. Tuvo dos experiencias laborales negativas que la impulsaron a buscar nuevos horizontes; el primer cambio fue el régimen de trabajo, esto es, pasar de "puertas adentro" a "puertas afuera". El tiempo libre que ganó lo invirtió en negocios paralelos, tales como la venta de comida (colaciones) a un costado de la calle Catedral, en el centro de Santiago. Beatriz se dio cuenta de la gran demanda por comida peruana y por el envío de encomiendas, pues son prácticas que mantienen el vínculo con aquellos que están en el país de origen, lo que la hizo pensar en dedicarse completamente a esta actividad comercial. El apoyo de su marido fue clave en este segundo cambio, pues le permitió salir definitivamente del trabajo doméstico e iniciar su propio negocio.

Los viajes constantes a Perú para llevar encomiendas y traer productos que vende en su local de la galería comercial (caracol), generaron en ella una experiencia migratoria nueva, pues comenzó a ser evidente que su vida transcurría entre ambos lugares. Sin embargo, los constantes viajes también van mostrando diferencias irreconciliables entre ellos. Santiago y Lima están conectados, pero son obviamente distintos, en la medida en que cada uno va adquiriendo significados diferentes. Es por ello que llama la atención su gusto por viajar, y la tranquilidad que dice sentir en el bus, que le permite descansar y dormir: "yo creo que no duermo tan bien, pero... cuando viajo jme las duermo todas!, pa" Arica todo durmiendo, me voy el viaje itodo durmiendo! Soy la bella durmiente". 
Como plantea Ahmed (1999), en los medios de viaje (buses, aviones, trenes) el sujeto tiene un destino, un futuro que otorga sentido de seguridad y propósito al movimiento. En este contexto, el viaje para Beatriz pareciera representar un tránsito constante, que permite complementar la vida en Perú y en Chile. Ambos lugares son partes incompletas de su vida, y los viajes son el mecanismo que hace posible intercambiar la ausencia y la presencia, de modo de acceder físicamente al lugar que se extraña en cuanto se vuelve lejano. En el caso de Beatriz, lo que posibilita estos viajes es su trabajo, pero no en cuanto consecuencia (trabajar para poder luego viajar) sino como superposición (viajar es el trabajo). En este transitar constante, los lugares van siendo resignificados y diferenciados por Beatriz: Chile como lugar de trabajo, de oportunidades laborales y proyectos familiares; Perú como un lugar de goce, de vida apacible, de propiedad. La distancia geográfica se vuelve también distancia simbólica, pues ambos lugares son complementarios pero imposibles de fundir en uno solo: "cuando hay eventos peruanos uno dice, uy parece Perú, pero no llena ese vacío; hay algo... Es como cuando dice ya pasa la frontera con Perú, como que el alma vuelve a su cuerpo" (énfasis propio).

El viaje permite recorrer la distancia que separa ambos lugares, de modo que el alma se reencuentre con el cuerpo. El viaje, en sus dimensiones espacial y temporal, es por tanto aquello que une y vincula, a la vez que separa y diferencia. Disfrutar del viaje es recordar que la vida transcurre necesariamente entre ambos mundos, pero que la distancia que los separa solo se puede recorrer, nunca eliminar.

...igual tengo mis cosas acá, pero esto como que no lo siento como mío, es algo extraño (...). Claro, cuando uno sale, cuando uno vuelve [a Perú] ya entra todo normal, después cuando uno sale como que deja, uno como que uno vive acá como préstamo, como que está de pasada nomás, más las cosas que pueda tener. Creo que a cualquier persona le pasa también, como si va a Argentina... no es suyo, aunque viva años.

$-¿$ Qué necesitas para que sea tuyo?

Nacer creo, nacer, pero igual [uno] tiene derecho, como chilena tiene derecho de todo... para trabajar aquí, cuando está legalmente, claro. Claro allá aunque uno sea pobre, todo, uno es feliz, porque es su país, donde ha nacido, sus costumbres, sus raíces, todo.

Para Beatriz, el trabajo adquiere total centralidad. Su vida transcurre en el local de comida que tiene en el caracol. Aquí es donde establece las relaciones con sus amistades y su familia, donde reproduce las prácticas cotidianas que le permiten mantener las formas de vida que asocia a su lugar de origen. Beatriz ha hecho de su local, su casa. Los negocios 
que ha montado son el testimonio de su experiencia migratoria, en donde intenta traer retazos de la vida en Perú al lugar donde vive. Preparar comida es una forma de recrear sabores que recuerdan el lugar ausente y las vidas pasadas. Por otra parte, el negocio de encomiendas (que también realiza desde su local) es lo que permite viajar una y otra vez a Perú.

El caracol de calle Catedral, donde se emplaza su negocio, es lo más cercano que tiene a su hogar, pues allí se siente como si estuviese en Perú, entre sus conocidos, familiares y amigos. La casa que ocupa en Santiago, en cambio, no la siente como un espacio propio: "ya nos queda chica la casa, nos queda chico y... igual... ya nos da como fobia... Digamos la sala, tenemos sala grande pero ni la utilizamos en el día". Las pocas horas que pasa allí, la ausencia de recuerdos y el hecho de no constituirse como espacio de convivencia, dificultan su apropiación. Casa y hogar se resignifican también a partir de la tensión que experimenta la dicotomía cuerpo / alma. Esto porque la casa se convierte en el lugar para dormir, donde el cuerpo descansa después de la jornada laboral, mientras que el local donde trabaja asume las características de hogar, pues ahí se junta con sus amigas, su familia, conversa y recuerda a Perú. La casa destaca por una ausencia de pertenencias significativas, constituyéndose en un habitar que no genera apropiación, lo que contrasta con los recuerdos y objetos que sí tiene en su local.

Como diversos estudios señalan, principalmente a través de las prácticas cotidianas (Dyck y Dossa, 2007) y posesiones del hogar (Miller, 2008; Tolia-Kelly, 2004), los migrantes se apropian del lugar que habitan y se identifican con este a través de una continua negociación entre elementos culturales del país de origen y destino (Dyck y Dossa, 2007). Este proceso de construcción de hogar (Bonhomme, 2011, 2013; ver Tolia-Kelly, 2004), en donde se construyen cotidianamente sentidos de pertenencia en el espacio privado, permite reflejar subjetivamente sus procesos de inserción en la ciudad receptora. Sin embargo, el espacio donde Beatriz construye un hogar no es necesariamente aquel donde habita, sino su lugar de trabajo, porque es allí donde genera un sentido de pertenencia y comienza a gestarse un arraigo en el país receptor. Solo en ese espacio (de trabajo) se siente a gusto, cómoda, segura, por lo tanto es coherente con su proyecto migratorio y con lo que significa Chile para ella. Su estrategia de inserción es a través del trabajo pues este cubre las necesidades básicas, y le permite recrear y reencontrar aquellos sentidos y significados que asocia a su cultura. 


\section{Giovanna. La familia como eje integrador}

Giovanna tiene 36 años, originaria de Cañete (costa central del Perú), casada con un chileno y tiene dos hijos nacidos en Chile, de 12 y 7 años, respectivamente. Hace 15 años que llegó a Chile. Ella evidencia un proceso de inserción social basado en la constitución de una familia, donde ha desarrollado su proyecto de vida. Su familia y la casa que habita la hacen sentir que este es el lugar donde se quedará a vivir.

Llegó sola después de que le ofrecieron un trabajo en Santiago a través de una agencia de empleo ubicada en Lima, cumpliendo su deseo de viajar y conocer otras culturas. El hecho de no conocer a nadie y de estar trabajando puertas adentro, la llevó a encerrarse aún más en su pieza dentro de la casa en la que estaba. Estuvo casi un año sin salir. Se sintió tremendamente sola y extrañaba su vida en Perú, sus amistades y las fiestas a las que concurría.

en general siempre he sido más aventurera, aventurera en el sentido de conocer, de querer saber de otras cosas... entonces era como bonito, qué buena onda... o sea como qué rico, voy a viajar. O sea nunca pensé en la soledad, nunca pensé en cuán triste me voy a sentir... ¡na’ de eso! Era como todo bonito al inicio al venirme... Al estar aquí propiamente tal, ya como que uno se queda sola, sola porque los amigos, el carrete... Yo carreteaba, o sea full carrete, o sea mis amigos eran de ahí, crecimos y estudiamos juntos, teníamos un grupo de amigos que salíamos a todas partes. Entonces... eso fue como lo que me hacía falta, porque en Chile yo no conocía a nadie (...) Y si salía conocía a alguien... de hecho como que yo soy un poquito... de seleccionar a mis amigos. Yo no me junto con cualquiera...

Fue un proceso de, de estar sola. De repente con la que salía era la Verónica, fue la primera que conocí y la primera que me llevó a Fantasilandia. Sipo, ella me dijo: "Giovanna, vayamos a Fantasilandia pa’ que conozcai Chile poh, ¿cómo vai a estar ahí sin hacer ná?... Ya, vamos a Fantasilandia"...Y ¿a cuál me subí?, al Boomerang, ese que estaba de moda recién, el amarillo ese, aaaahhh. No y me subí y yo aaahh. Y la otra me decía: "igrita!", porque al gritar como que si uno pierde... y yo quede como aaaahhh, no podía respirar... la velocidad que traía... y ella me pegaba una manotá en la espalda y me decía "igrita!", y como que me quitó los nervios igual... exquisito (énfasis propio).

Todo el silencio del encierro y la soledad que experimentó se sintetiza en ese grito, que para ella marca un punto de inflexión en su trayectoria migratoria pues a partir de ahí decide salir y vivir nuevas experiencias. 
Después de un tiempo la empleadora la despidió, convirtiéndose en un momento de profunda decepción, lo que marca el relato. Señala que fue despedida sin motivos, y que la empleadora no cumplió su palabra ni el contrato firmado. Más tarde agrega que fue demandada por un robo que nunca cometió. De inmediato encontró un nuevo trabajo con una empleadora que fue muy significativa en su vida, y que luego la recomendó entre sus amistades para que comenzara a trabajar "puertas afuera". En el intertanto conoció a una amiga también peruana, con quien comenzó a salir a fiestas y reuniones. En la primera fiesta a la que fueron conoció a su actual marido. Comenzaron a salir y luego a pololear. Quedó embarazada y comenzaron a buscar un lugar estable para vivir. Antes de tener a su primer hijo, Giovanna trabajaba "puertas adentro", pero luego comienza a hacerlo "puertas afuera" porque quería dedicarse a su familia.

Gracias al trabajo de su marido como obrero de la construcción, consiguen acceder a un programa de vivienda. Actualmente viven en Colina en una casa propia, barrio al cual también se mudaron sus suegros, quienes la apoyan en el cuidado de sus hijos y son para ella, su nueva familia. La compra de la casa junto con la inversión en decorarla y ampliarla, reflejan aspectos de su proceso de inserción y evidencian el distanciamiento con su familia de Perú: "hay que adaptarse al lugar, no el lugar se adapta a ti". Por ello no se permite sentir nostalgia ni extrañar a su familia, ya que decidió deliberadamente construir una nueva familia, la propia.

Giovanna ha logrado asentarse lejos de Santiago Centro u otras comunas con mayor población de inmigrantes, lo que la ha llevado a alejarse de sus antiguas amistades. Pocas veces ha viajado a Perú. Así, de a poco ha ido tejiendo redes en Chile a través de su familia directa, y destejiéndolas respecto de Perú. Su modo de hablar, la comida que prepara, todo se ha ido volviendo cada vez más chileno. Sin embargo, pese a llevar 15 años y a mantener muy pocas conexiones con Perú, ella enfrenta el extrañamiento de la sociedad a través de sus hijos. Ellos, habiendo nacido en Chile y teniendo a su papá chileno, son reconocidos como peruanos por su pares en la escuela. Una categoría que en ese contexto establece diferencias, separa y excluye. Si en el caso de Beatriz, sentirse completamente parte de la sociedad de llegada supondría haber nacido en Chile, Giovanna experimenta la impotencia de que sus hijos, siendo chilenos, son igualmente marcados con una categoría que adquiere un significado peyorativo y riesgoso en el contexto nacional.

No si de que hay discriminación, hay discriminación. Y mi hija también la siente. Gracias a Dios a ella no le ha pasado na.' Tenía un compañerito que la molestaba, le decía por ejemplo que ella era negra porque la mamá era peruana... cosas así. Pero el niñito era moreno-moreno... eso era lo raro. O sea ni siquiera sabe lo que dice porque si está hablando de piel, él 
era mucho más moreno que ella...moreno-moreno. Mi hija es como mate... él era moreno (...). En el fondo empezai a sentir culpa y decí: "ay que lata y por qué seré hija de no sé qué, si no fuera así no me molestarían”... Por eso yo le digo que ella tiene que estar fuerte en ese sentido, nunca dejar que alguien le haga daño (...) para que no crezca con resentimiento (...) Yo los crío tratando de que nadie les haga daño, tratando de que no tenga ese rencor.

Tú no puedes renegar de tu piel porque es como renegar de tu pasado, de tu familia y aparte que no importa, la piel va a envejecer y se va a ir, no sirve de nada, es un caparazón que te cubre.

El significado que los compañeros de clase le atribuyen al color de piel se vuelve una amenaza de discriminación para los hijos de Giovanna (Tijoux, 2013b). En el colegio, el color de la piel se transforma en una marca que distingue, diferencia y jerarquiza. Giovanna intenta convencer a sus hijos que no existe tal diferencia, que los colores son iguales y que incluso hay niños chilenos más morenos que ellos, pero los procesos de construcción y estratificación del migrante ya están en marcha, y en ese momento, poco importa el "real" color de la piel. En un segundo intento por ayudar a sus hijos, Giovanna les enseña que deben sentirse orgullosos de sus tradiciones y su origen. Este fragmento devela las dificultades que enfrenta la interculturalidad, pues la alteridad es reconstruida y jerarquizada una y otra vez por la sociedad dominante. Frente a ello, la única salida que avizora la entrevistada es el resguardo de sus hijos al interior del hogar, un espacio de tranquilidad y seguridad donde desaparecen las marcas sobre las cuales se construye la separación y exclusión presentes en el espacio público. De ahí la importancia que reviste el hogar para Giovanna, pues frente a la ausencia de políticas interculturales, que promuevan la inclusión de la diversidad en el ámbito público, su familia encuentra en el ámbito privado un espacio de contención, respeto y crecimiento.

Con el tiempo, Giovanna ha ido incorporando modismos chilenos en su hablar y prácticas locales, como la comida. Ella representa un claro ejemplo de inserción a través de la familia, pues esta constituye el eje en su experiencia migratoria. Construir su hogar en Chile requirió, sin embargo, desvincularse de su lugar de origen, para sentir que estaba formando algo nuevo y propio. De ahí que la forma como habita y decora su casa son muy similares a las de una familia chilena. Sin embargo, mantiene en el discurso el orgullo de ser peruana, un discurso que devela una reivindicación identitaria que le permite mantener un arraigo propio en una vida que, a primera vista, pareciera estar bastante asimilada al entorno chileno. 


\section{Delsy. Inserción por redes sociales}

Delsy tiene 45 años, es de Arequipa, casada con una persona de origen peruano y tiene dos hijos nacidos en Chile, de 16 y 10 años. Hace 19 años que llegó a Chile para trabajar como enfermera en un hospital. Su relato revela cuán importante es para ella sentirse "como si" estuviera en Perú, por lo que sus amistades (de origen peruano) son un elemento central para su inserción laboral y social. La comunidad peruana es el eje principal a través del cual logra una inserción fluida que le permite estar en dos mundos a la vez.

Su llegada a Santiago estuvo marcada por el miedo a lo desconocido. Comienza prontamente a trabajar en un hospital, donde conoce a mujeres peruanas de su misma ciudad, con quienes entabló una larga amistad. Para Delsy, 'ser peruano o peruana' es una categoría de inclusión y pertenencia, pues basta con el hecho de ser original de ese país para comenzar a conversar y entablar amistades.

me senté en una mesa cerca, y en eso voltea una niña, y me mira y me dice "Delsy", y era una vecina de allá del lugar en donde yo vivo en Arequipa, ella vive como a espaldas de mi casa de allá de Arequipa, y nos venimos a encontrar acá, y allá en Arequipa nos saludábamos de hola, hola, pero viviendo cerca, a la vuelta prácticamente, y no teníamos confianza... de hola, hola nomás. Y cuando nos vimos... nos abrazamos como si fuéramos las grandes amigas jajaja, y yo no conocía a nadie más de ahí, así que... pero terminamos siendo grandes amigas, con todo ese grupo que llegó. Trabajábamos todas de 12:00 a 17:00 en ese entonces, nos reuníamos los días viernes, por ejemplo, que salíamos a las cuatro de la tarde del hospital... y nos íbamos a pasear por el centro, nos íbamos a buscar los restoranes peruanos, ahí escuchábamos la música peruana que tocaban, comíamos los platos peruanos. O sea era como que estuviéramos en casa. En ese entonces me acuerdo que era por allá por Brasil, parece... la Avenida Brasil, por allá había un restorán de comida peruana, con música, con todo.

Delsy, pese a los años en Chile y a tener hijos chilenos, no deja de vincularse con Perú, ya sea a través de la música, la comida o las llamadas telefónicas, lo que facilita el proceso de asentamiento y el desarrollo de estrategias identitarias asociadas a ambos lugares (Petridou, 2001). Recrear las tradiciones con sus connacionales desarrolla un sentido de pertenencia a una comunidad y hace visible su identidad en-el-hacer (Fortier, 2000).

como que están las ganas... eso me gustaría a mí que se llevara a cabo, y todos los años seguir las fiestas que hacíamos allá mantenerlas acá... Es que a mí yo siento que me falta para seguir manteniendo nuestras tradiciones, eso me gustaría... 
¿Qué hago yo?... yo trato, antes, más que ahora, pero trato de juntarme con unas amigas que son peruanas y tratamos digamos de celebrar las fiestas que son típicas que se celebran en Perú, el día de mi ciudad y como le digo las cosas típicas de allá. Yo tengo harta música peruana, allá pero tienen cantidad de música peruana, así como las comidas, cada ciudad tiene su camino como la música, entonces yo tengo música y tanto mantenerlo eso, yo le hablo a mis hijos de esto, las fiestas. Mira, hijo, se celebra tal cosa allá y se hace tal cosa y se toca música o se baila tal danza, entonces trato yo de meterle y siempre que puedo. Por ejemplo, acá en la embajada peruana en el Consulado, hacen algunos eventos. Siempre que puedo voy, trato de no perderme y comimos la comida que cocinan, siempre todos los platos en base a lo que se come.

Estar con amigos es estar en familia. El trabajo, por lo tanto, no es una esfera de inserción en sí misma, sino en cuanto le ha permitido encontrar amistades a través de las cuales logra mantener un vínculo con su país. Como plantea Georgiou (2006, p. 45), la construcción de identidad implica no solo un proceso psicológico sino también "la conformación de un sentido de pertenencia compartido y común con otros y contra otros", reconfigurando la identidad a través de la membresía a una comunidad que a su vez se distingue de la cultura hegemónica en el caso de los y las migrantes. En este sentido, Delsy se "encuentra" a sí misma al participar de la identidad de una colectividad (Georgiou, 2006). A través de las amistades, Delsy tiene la posibilidad de rehabitar los espacios y lugares en Chile, siendo fundamental el rol de esta comunidad originaria, que permite reactualizar la memoria común (Ahmed, 1999) en sus procesos personales de integración.

yo me sentía como en la casa, o sea fascinada, nosotros cantando porque... la música peruana es muy bonita, es como melancólica, entonces cuando nosotros nos reuníamos íbamos al restorán peruano, y nos poníamos a cantar y no faltaba que una ya se ponía triste, se ponía a llorar, y el resto terminábamos todas llorando cuando estábamos en el restorán, porque la música, o sea, hay mucha gente que así como yo, que nunca jamás en su vida había salido a un lugar tan lejos.

La comparación entre Chile y Perú es constante en su relato, y a través de ella otorga valor a su país natal por sobre Chile, ya sea respecto de la educación, los precios de las cosas, el clima, u otros asuntos. Al igual que Beatriz, existe una idea particular del origen como algo determinante que marca la identidad y las prácticas culturales. Pese a respetar y promover la pertenencia originaria y cultural de sus hijos chilenos, sus propias prácticas cotidianas procuran recordar y mantener actualizados sus orígenes peruanos, aunque siempre desde la libertad de elección e identificación de sus hijos con esta cultura. 
Perú es un elemento significativo en su vida e intenta enseñarles a sus hijos sobre sus raíces, reflejando también una yuxtaposición contante de ambas culturas. Es así como busca que sean los propios niños los que resignifiquen tanto la categoría de peruanidad como su chilenidad, para llenarlas de un significado positivo.

hay que hacerlos a ellos que quieran, que sientan cariño, amor y respeto por su patria y que sepan respetar sus tradiciones... yo igual por ejemplo algunas veces me dicen: "mamá... esa música", bueno, le digo: "hijo, es mi música". Igual cuando eran chicos sobre todo yo tenía un disco de cuecas y para las fiestas le ponía siempre su disco de cuecas o sea como para que ellos comiencen a identificarse y como te digo, querer amar a su país y respetar sus fiestas; de chico fíjate al Rodrigo sobre todo, él pedía que lo vistan de huaso, cómo le gustaba que lo vistan de huaso de chico.

La respuesta de los niños da cuenta de la adaptabilidad como estrategia de inserción, ya que modifican su acento según la presencia de uno u otro interlocutor. Así, con sus amigos hablan "en chileno" y con sus padres hablan con acento peruano. Esto se corresponde con el concepto de alternancia planteado por LaFromboise et al. (1993 en Birman 1998) y Phinney y Devich-Navarro (1997 en Birman 1998), que es un tipo de biculturalismo donde, dependiendo del entorno cultural en que se sitúen, las personas se sienten aculturadas en uno u otra cultura.

nosotros tenemos una forma de hablar distinta..., entonces cuando llegó al colegio (...) los primeros años, lo molestaban, le decían "peruanito", y él venía enojado: "yo no soy peruano, yo soy chileno". Yo le explicaba: "sí, hijo, tú eres chileno, porque tú naciste acá en Chile, tú eres chileno, pero por tus venas corre sangre peruana", le digo, "porque tu padre es peruano, yo soy peruana, entonces no les hagas caso a los compañeros... porque tú tienes dos nacionalidades, tú eres chileno y eres peruano, no les hagas caso, de envidia te dicen, peruanito, peruanito". Y ya lo aprendió, y ya... ya no se enojaba. Decía "no, me decían, peruanito, peruanito", y el optó por ejemplo, con cada uno de nosotros hablaba bien como peruano, cuando estaba con sus amigos era como un cambio, era un chileno hablando. Un cambio en su forma de comportarse, en su forma de hablar, era... era porque se sentía molesto, no le gustaba que le digan que era peruano.

Delsy tiene casa propia y no pretende volver a Perú por el momento, principalmente por sus hijos. Sin embargo, mantiene viva su pertenencia, al igual que Beatriz: " $o$ sea a mí me gusta Chile, me gusta, pero yo creo que igual uno nunca se olvida de su tierra, de sus costumbres". La casa para Delsy entonces se convierte en un proyecto que la ancla 
a Chile, pero donde intenta recrear su cultura y plasmar aquellos elementos identitarios que considera relevantes, por ejemplo la música.

Chile pasa a ser un lugar geográfico que le otorga oportunidades laborales y el locus de realización personal, donde a su vez puede mantener contacto y vivir su cultura a diario a través de su pertenencia a una comunidad peruana. De esta manera, el eje en su proceso de inserción lo constituyen las redes sociales y pertenencia a una comunidad mayor, y es así como Perú está presente en sus prácticas cotidianas, viviendo simultáneamente en su hogar dos culturas, dos mundos, reproduciendo o más bien "localizando" Arequipa en Santiago.

\section{Conclusiones}

Si bien el trabajo es una de las razones principales del proyecto migratorio, es solo uno de los ejes que articulan las trayectorias y los procesos de inserción de los migrantes en las sociedades de destino. Ahora bien, estas trayectorias están determinadas por las condiciones económicas, sociales y políticas presentes en la sociedad de llegada, así como por los capitales sociales, culturales y económicos que traen los migrantes. La relación entre estos elementos va enfatizando ciertos ejes en la construcción de la trayectoria. Así, familia, trabajo y redes sociales emergen como hilos conductores que estructuran y dan sentido a las trayectorias de las mujeres.

Las relaciones familiares son fundamentales para el asentamiento en la sociedad de destino (Olwig, 1998) y uno de los pilares que articulan la experiencia migratoria (Stefoni, 2009). La familia en estos tres relatos es un eje transversal en las decisiones que las mujeres inmigrantes toman, definiendo sus posibilidades de trabajo y negocios, sus viajes a Perú y sus proyectos futuros. En el caso de Giovanna, no tener familia en Perú la impulsó a emigrar, una vez que formó su familia en Chile, todo su proyecto se volcó a lograr estabilidad y buenas condiciones para sus hijos, acostumbrándose a llevar una "vida chilenizada" y postergando sus deseos de retorno. Beatriz, una vez que se reunifica con su familia de Perú, logra explorar nuevos negocios que no hubiesen sido posibles sin el apoyo de su marido e hijo, y la inserción laboral de ella y su familia, así como el nacimiento de su nieta, hace que postergue también su retorno. Los viajes y estancia en Arica de Delsy permiten mantenerla cercana a su madre. Sin embargo, su nueva familia requiere que esté en Santiago. 
La mantención de vínculos sociales con otros migrantes peruanos permite intercambiar información relevante respecto de la ciudad de destino, y a la vez minimizar los costos de la distancia, ya que permiten constituir una comunidad que amplía las redes, haciendo de la migración, una experiencia positiva. Sin embargo, Giovanna desde un principio se mantiene alejada de tal comunidad. Cuando se casa con su actual marido chileno, deciden ir a vivir lejos de los barrios que tienen una alta proporción de población extranjera, lo que acentúa el quiebre con la comunidad de migrantes y facilita la incorporación de hábitos y tradiciones chilenas. Según Dribe y Lundh (2008), el matrimonio entre un inmigrante y una persona nativa permite que su integración sea más rápida, especialmente en términos laborales y económicos.

La relación constante con los connacionales es lo que permite a Beatriz y Delsy mantener un sentido de pertenencia con el lugar de origen, manteniendo tradiciones e incluso su acento. La existencia de ciertos enclaves de migrantes las hace sentir "como en casa", en un espacio transnacional que recrea costumbres a la vez que incorpora elementos del mundo de llegada (Schiller, Basch, y Blanc-Szanton, 1992). Como Georgiou (2006) explica, la vida cotidiana de Beatriz y Delsy está mediada por la coexistencia local, interacción y reproducción visual de la comunidad en la que están inmersas, que las hace relacionarse presencialmente con personas de su mismo origen, y el ser conscientes de ello, las hace apreciar aún más su cultura, generando así una comunidad transnacional, una comunidad imaginada (Anderson, 2006) que se vuelve un pilar fundamental en su proceso de inserción.

La interacción constante de la cultura chilena y peruana genera un "estar-aquí" para "sentirse-allá", como es el caso de Delsy. La casa convertida en hogar - como un lugar apropiado significativamente por el ocupante- se constituye en un lugar simbólico y real que implica familiaridad, intimidad, seguridad e identidad, que protege contra la distancia y lo desconocido. Sin embargo, en el caso de las y los inmigrantes, el hogar es incompleto y ambiguo, ya que lo simbólico y lo real no siempre van de la mano, sino que tiene límites borrosos. El hogar en este sentido no implica una casa necesariamente, sino más bien se transforma en un concepto mayor, en un hogar que se encuentra en la interacción con una comunidad que mantiene y reproduce su pertenencia originaria, tanto para Delsy como para Beatriz. Tal como Hall (1992) explica, para sentir subjetivamente quiénes somos es fundamental mantener relatos identitarios y comprender que nuestro discurso proviene de un lugar, experiencia y cultura particular, por lo tanto todo migrante necesita expresar su identidad a través de reproducir sus costumbres y tradiciones. A su vez, la identidad está relacionada con posicionarse dentro de una cultura, moldeando 
el sentido de pertenencia a través de apropiarse de tales patrones culturales (Georgiou, 2006).

Muchos estudios discuten acerca de los procesos de inserción de inmigrantes desde aspectos formales de la sociedad de destino, sin embargo, pocos reflexionan acerca de cómo ha sido esta inserción desde la mirada experiencial de la propia persona que la vive, la cual va más allá de lo legal, y no ve personas sino sujetos inmigrantes. Revelar los procesos de inserción desde una dimensión subjetiva - principal propósito de este artículo- es necesario para entender cuáles han sido sus dificultades, cómo han logrado superarlas, cuáles han sido los caminos escogidos y cómo se definen ellos dentro de una sociedad que parece ignorar sus derechos como ciudadanos iguales. Es por ello que consideramos crucial resaltar la importancia de considerar las percepciones de los mismos migrantes a la hora de elaborar políticas públicas relativas a la integración social. Sin pretender una asimilación completa, las y los migrantes buscan compartir un espacio donde sean tratados como iguales pero cohabitándolo desde su cultura y experiencia, sin dejar, necesariamente, de lado sus raíces y creando arraigos múltiples que remiten a uno u otro mundo en la cotidianeidad. Chile se presenta como una oportunidad para desarrollarse y a la vez aportar con su trabajo, cultura y modos de vida, que permiten el desarrollo de una diversidad cultural y el consiguiente respeto y tolerancia mutua. 


\section{Referencias}

Acosta, E. (2013). Entre la necesidad y el no-reconocimiento: La valoración de la dimensión temporal en las estrategias familiares para la contratación de cuidadoras domésticas inmigrantes en España y Chile. Si Somos Americanos. Revista de Estudios Transfronterizos, XIII (2), 141-164.

Ahmed, S. (1999). Home and away: Narratives of migration and estrangement. International Journal of Cultural Studies, 2 (3), 329-347.

Anderson, B. (2006). Imagined Communities: Reflections on the origin and spread of Nationalism. Londres, Inglaterra: Verso.

Bhabha, H. K. (1996). Culture's In-between. En Stuart Hall y Paul Du Gay (Eds.), Questions of Cultural Identity (pp. 53-60). Londres, Inglaterra: Sage.

Beccera, M., Altimir, L. y Solis, A. (2012). ¿Quién es el paciente migrante y cómo se manifiesta su malestar? Revista Psicología Hoy, 15. Recuperado de http://psicologia.uahurtado. cl/2013/01/quien-es-el-paciente-migrante-y-como-se-manifiesta-su-malestar/

Beck, U. (2000). La democracia y sus enemigos. Textos escogidos. Barcelona, España: Paidós.

Birman, D. (1998). Biculturalism and perceived competence of latino immigrant adolescents. American Journal of Community Psychology, 26 (3), 335-354.

Bonhomme, M. (2011). Chilean women making home in London. Tesis para optar al grado de Magíster, London School of Economics and Political Science, Londres, Inglaterra.

-__—. (2013). Cultura material y migrantes peruanos en Chile: un proceso de integración desde el hogar. Polis, 12 (35), 63-84.

Canclini, N. G. (1990). Culturas híbridas. Estrategias para entrar y salir de la modernidad. México, México: Grijalbo.

Cano, V., Soffia, M. y Martínez, J. (2009). Conocer para legislar y hacer política: los desafíos de Chile ante un nuevo escenario migratorio. Serie Población y Desarrollo, $\mathrm{N}^{\circ} 88$. Santiago, Chile: CEPAL / CELADE. 
Dribe, M. y Lundh, C. (2008). Intermarriage and immigrant integration in Sweden: An exploratory analysis. Acta Sociológica, 51 (4), 329-354.

Ducci, M. E. y Rojas, L. (2010). La pequeña Lima. Nueva cara y vitalidad para el centro de Santiago de Chile. EURE, 36 (108), 95-121.

Dyck, I. y Dossa, P. (2007). Place Health and home: Gender and Migration in the Constitution of Healthy Space. Health and Place, 13, 691-701.

Fortier, A. M. (2000). Migrant Belongings: Memory, Space, Identity. Oxford, Inglaterra: Berg.

Garcés, A. (2013). Urbanidades en pugna: usos y memorias de espacio en la migración peruana en Santiago de Chile. En V. Correa, I. Bortolotto y A. Musset (Eds.), Geografías de la espera. Migrar, habitar y trabajar en la ciudad de Santiago de Chile 1990-2012 (pp. 251-284). Santiago, Chile. Uqbar editores.

. (2014). Comercio ambulante, agencia estatal y migración: crónica de un conflicto en Santiago de Chile. En W. Imilan, A. Garcés y D. Margarit (Eds.), Poblaciones en movimiento. Etnificación de la ciudad, redes e integración (pp. 147-166). Colección de Antropología. Santiago, Chile: Universidad Alberto Hurtado.

Georgiou, M. (2006). Diaspora, Identity and the Media: Diasporic Transnationalism and Mediated Spatialities. Nueva Jersey, Estados Unidos: Hampton Press Cresskill.

Godoy, L. (2007). Fenómenos migratorios y género: identidades femeninas 'remodeladas'. Revista Psykhe, 16 (1), 41-51.

Guizardi, M., Heredia, O., Muñoz, A., Riquelme, G. y Valdebenito, F. (2013). Experiencia migrante y apropiaciones espaciales. Una etnografía visual en las inmediaciones del Terminal Internacional de Arica (Chile). Revista Estudios Sociales, 48, 166-175.

Hall, S. (1992). New ethnicities. En J. Donald y A. Rattansi (Eds.), 'Race', culture and difference (pp. 252-259). Londres, Inglaterra: Sage.

Hondagneu-Sotelo, P. (2007). Domestica: Immigrant Workers Cleaning and Caring in the Shadows of Affluence. Berkeley y Los Ángeles, Estados Unidos: University of California Press. 
Imilán, W. (2013). Restaurantes peruanos en Santiago de Chile: construcción de un paisaje de la migración. Revista de Estudios Sociales, 48, 15-28.

Levitt, P. y Glick Schiller, N. (2004). Conceptualizing simultaneity: A transnational social field perspective on society. International Migration Review, 38 (3), 1.002-1.039.

Martínez, J. (2003). El encanto de los datos. Sociodemográfica de la inmigración en Chile según el censo de 2002. Serie Población y Desarrollo, $\mathrm{N}^{\circ}$ 49. Santiago, Chile: CEPAL / CELADE.

Miller, D. (2008). The Confort of Things. Cambridge, Reino Unido: Polity Press.

Mora, C. (2008). Globalización, género y migraciones. Polis, 7 (20), 285-297.

. (2009). Estratificación social y migración intrarregional: algunas caracterizaciones de la experiencia migratoria en Latinoamérica. Universum, 24 (1), 128-143.

Mujica, J. (2004). El desafío de la solidaridad. Condiciones de vida y de trabajo de los migrantes peruanos en Chile. Serie $N^{\circ} 178$. Lima, Perú: Organización Internacional del Trabajo OIT.

Olwig, K. F. (1998). Epilogue: Contested Homes: Home-making and the Making of Anthropology. En N. Rapport y A. Dawson (Eds.), Migrants of Identity: Perceptions of Home in a World of Movement (pp. 225-236). Oxford, Inglaterra: Berg.

Pavez, I. (2012). Inmigración y racismo: experiencias de la niñez peruana en Santiago de Chile. Si Somos Americanos. Revista de Estudios Transfronterizos, XII (1), 75-100.

- (2013). Los significados de 'ser niña y niño migrante': conceptualizaciones desde la infancia peruana en Chile. Polis, 12 (35), 183-210.

Petridou, E. (2001). The taste of home. En D. Miller (Ed.), Home possessions: material culture behind closed doors (pp. 87-104). Oxford, Inglaterra: Berg.

Russell, A. (2000). Global care chains and emotional surplus value. En A. Giddens y W. Hutton (Eds.), On the edge: living with global capitalism (pp. 130-146). Londres, Inglaterra: Jonathan Cape. 
Staab, S. y Hill, K. (2006). The dual discourse about Peruvian domestic workers in Santiago de Chile: class, race and nationalist project. Latin American Politics and Society, 1 (48), 87-116.

Schiller, N. G., Basch, L. y Blanc-Szanton, C. (1992). Transnationalism: A new analytic framework for understanding migration. Annals of the New York Academy of Sciences, 645 (1), 1-24. doi:10.1111/j.1749-6632.1992.tb33484.x

Simmel, G. (1986). Sociología I y II, Estudios sobre las formas de socialización. Madrid, España: Alianza Editorial.

Stefoni, C. (2009). Migración, género y servicio doméstico. Mujeres peruanas en Chile. En M. E. Valenzuela y C. Mora (Eds.), Trabajo doméstico: un largo camino hacia el trabajo decente (pp. 191-232). Santiago, Chile: Organización Internacional del Trabajo OIT.

. (2011). Perfil Migratorio de Chile. Buenos Aires, Argentina: Organización Internacional para las Migraciones OIM.

Stefoni, C. y Fernández, R. (2011). Mujeres inmigrantes en el trabajo doméstico: entre el servilismo y los derechos. En C. Stefoni (Ed.), Mujeres inmigrantes en Chile: ¿mano de obra o trabajadoras con derechos? (pp. 43-72). Colección Sociología. Santiago, Chile: Universidad Alberto Hurtado.

Tapia, M. (2012). Frontera y migración en el norte de Chile a partir del análisis de los censos de población. XIX-XXI. Revista de Geografía de Norte Grande, 53, 177-198.

Thayer, E. (2013). Expectativas de reconocimiento y estrategias de incorporación: la construcción de trayectorias degradadas en migrantes latinoamericanos residentes en la Región Metropolitana de Santiago. Polis, 12 (35), 259-285.

Tijoux, M. E. (2007). Peruanas inmigrantes en Santiago. Un arte cotidiano de la lucha por la vida. Polis, 18. Recuperado de: http://polis.revues.org/4185

(2013a). Niños (as) marcados por la inmigración peruana: estigma, sufrimientos, resistencias. Convergencia. Revista de Ciencias Sociales, 61, 83-104.

. (2013b). Las escuelas de la inmigración en la ciudad de Santiago. Elementos para una educación contra el racismo. Polis, 12 (35), 287-307. 
Todorov, T. (1990). El cruce de las culturas. Criterios, 25-28, 3-19.

Tolia-Kelly, D. (2004). Locating process of identification: Studying the precipitates of re-memory through artefacts in the British Asian Home. Transactions of the Institute of British Geographers, 29 (3), 314-329. 